\title{
Two Steps Forward, One Step Back: A Policy Analysis of the Swedish Guidelines for Trans-Specific Healthcare
}

\author{
Ida Linander ${ }^{1}$ (D) Marcus Lauri ${ }^{2} \cdot$ Erika Alm $^{3} \cdot$ Isabel Goicolea ${ }^{4}$ \\ Published online: 25 May 2020 \\ (C) The Author(s) 2020
}

\begin{abstract}
Introduction Sweden has one of the world's longest histories of providing subsidized gender-confirming medical procedures for people with trans experiences. However, until 2015, Swedish trans-specific healthcare lacked formal guidelines.

Methods In this study, we analyse the Swedish guidelines for trans-specific healthcare from 2015 using Bacchi's approach: "What's the problem represented to be?" Following this approach, we analyse problem representations in the guidelines with special focus on evaluation, diagnosis of gender dysphoria and criteria for access to care.

Results Three problem representations were identified in our analysis: "the problem of (non)linear gender", "the mental health paradox" and "gender dysphoria as a psychiatric, psychological and psychosocial problem". Together, these problem representations construct gender dysphoria as a psychopathology and allocate the decision-making power to mental health care providers. Hence, the guidelines reconstruct the gatekeeping function among care providers while undermining care seekers' ability to attain self-determination. While the guidelines do allow for non-linear embodiment, they simultaneously reconstruct a linear relationship between gender identity and social gender role. Mental healthiness and, for migrants, having a residence permit seem to be favoured in the evaluation of gender dysphoria and for access to gender-confirming medical procedures, while aspects of gender euphoria are silenced.

Conclusions We conclude that the guidelines resemble, and have similar effects to, the psychomedical understandings of gender dysphoria prevalent in medical research and practice. At the same time, the guidelines attempt to depathologize trans experiences and open up space for new subjectivities to be eligible for access to gender-confirming medical procedures.

Policy Implication The knowledge from this study can be useful when constructing, revising or analysing guidelines for transspecific healthcare in several contexts.
\end{abstract}

Keywords Transgender $\cdot$ Gender dysphoria $\cdot$ Access to care $\cdot$ Sex reassignment $\cdot$ Mental health $\cdot$ Policy analysis

\section{Abbreviations \\ DSM Diagnostic and Statistical Manual of Mental Disorders \\ ICD International Statistical Classification of Diseases and Related Health Problems}

Ida Linander

ida.linander@umu.se

1 Department of Epidemiology and Global Health and Umeå Centre for Gender Studies, Umeå University, SE-901 87 Umeå, Sweden

2 Department of Psychology and Social Work, Mid Sweden University, Östersund, Sweden

3 Department of Cultural Sciences, Gothenburg University, Gothenburg, Sweden

4 Department of Epidemiology and Global Health, Umeå University, Umeå, Sweden

\section{SKS Swedish Knowledge Support \\ RLE Real Life Experience \\ WPR What's the problem represented to be?}

\section{Background}

For at least a hundred years, experiences of non-linear gender have been reported in the medical literature (Benjamin, 1966; Hirschfeld, 1910), and many people with such experiences have sought access to gender-confirming medical procedures (Dhejne, Öberg, Arver, \& Landen, 2014; Lane et al., 2018). While access to care is dependent on private means in many countries, trans-specific care in Sweden is included in the general healthcare insurance. However, several studies have shown that access to trans-specific care, both in Sweden and elsewhere, is conditional and that gender is normatively 
constructed in such care (Bremer, 2011; Dewey \& Gesbeck, 2017; Linander, Alm, Goicolea, \& Harryson, 2019; Spade, 2006).

In 1972, Sweden was the first country in the world to introduce a law regulating access to legal and genital gender reassignment (SFS, 1972:119). However, in 2010, a government report concluded that Swedish trans-specific care practices lacked conformity in terms of evaluation, treatment and waiting times (The National Board of Health and Welfare, 2010). Following this, in 2015, the National Board of Health and Welfare published and disseminated guidelines concerning the "evaluation, healthcare and treatment" of adult persons with gender dysphoria throughout the Swedish healthcare system (The National Board of Health and Welfare, 2015). These guidelines are the focus of our analysis.

Policies have become increasingly important in the organization and governing of healthcare practices (Coveney, 2010; Walt et al., 2008). Policies can be analysed in different ways, and the focus of policy analysis has shifted somewhat away from asking "what governments do, why they do it and what difference does it make?" (Coveney, 2010, p. 515) to focus more on policy as productive. This means asking questions about how policies provide tools for government by giving shape to and constructing problems in particular ways, rather than merely providing solutions to already existing problems (Bacchi, 2009; Coveney, 2010).

Following such cues, the aim of this study is to analyse problem representations in the Swedish guidelines for transspecific healthcare (SKS), using Bacchi's post-structural approach "What's the problem represented to be?" (WPR) approach (Bacchi, 1999, 2009). We will focus on problem representations in the recommendations for the evaluation and diagnosis of gender dysphoria and in the criteria for access to gender-confirming medical procedures in the guidelines. This can provide insights into constructions of gender identity and mental health, as well as elucidating processes of decision-making and access to care.

In line with this approach, we see policy suggestions for specific actions and solutions as building on an inherent understanding of a problem while simultaneously constructing that problem, regardless of what articulated problems the policy is said to address. This suggests that there are multiple ways to understand a phenomenon and that by emphasizing one particular understanding, policies block and silence alternative understandings. Analysing the Swedish guidelines for transspecific healthcare may thus provide important insights into what the problem of "gender dysphoria" and transspecific care is represented to be. Such representations may have consequences that extend beyond those of care-seekers. For example, the way in which trans bodies are constructed as deviant and in need of correction affects how gender itself is constructed.
As previous research based on interviews with careseekers has shown, access to gender-confirming medical procedures is connected to gender norms (Bremer, 2011; Dewey \& Gesbeck, 2017; Linander et al., 2019). Consequently, analysing the formal guidelines is an important endeavour, which may provide insights into the regulation of knowledge and individual subjects through policies. To the best of our knowledge, these guidelines have not been analysed before.

\section{Methods}

\section{Methodological and Theoretical Approach}

Bacchi draws upon Foucauldian perspectives on power and problematization in order to develop her tool for critically analysing policies (Bacchi, 1999, 2009). A basic assumption in Bacchi's approach is that policies do not (only) address existing problems, but (also) produce and give shape to problems (Bacchi, 1999). Such an approach stems from the understanding that problematization is not about representing a preexisting object but is rather a set of practices entering into a terrain of competing constructions of truth and falsehood. It is impossible to represent, or to have contact with, a value-free or interpretation-free reality and, therefore, the representation of problems in policies is not a set of objective descriptions of a pre-existing reality but rather consists of contested claims about the nature and existence of social problems (Bacchi, 1999). By analysing the proposals, suggestions and solutions in policy documents that are supposed to address a problem, we can learn something about how that "phenomenon" is constructed.

This approach means asking what implications these particular representations of the problems may have. Bacchi accounts for three effects of problem representations (Bacchi, 2009). Discursive effects focus on how problem representations contribute to shaping knowledge about a "phenomenon", for instance, how gender dysphoria itself is understood. Subjectification effects mean that policies contribute to constructing particular subjects, such as normal and knowledgeable care-providers and care-seekers. Lived effects focus on material consequences, such as access to care or care-seekers' ability to make decisions about medical procedures. It is especially important to discuss the lived effects for care-seekers, because studies of trans-specific healthcare have been criticized for lacking such a perspective (Bremer, 2011; Spade, 2006).

Using the WPR method does not mean that we understand the authors or responsible institutions behind the guidelines as having any particular intentions beyond the problem they set out to address. Instead, we understand the production of policy to consist of contested claims about the nature and 
existence of problems, and that policy development is affected by and may affect dominant discourses. Hence, this paper aims to problematize and highlight things that are taken for granted, making it possible to scrutinize them and open up possibilities for change (Foucault, 1991, p. 84).

The WPR approach has a critical theoretical underpinning (Bacchi, 2009) but does not provide a normative theoretical framework when it comes to trans experiences, so we will use theoretical and ethical insights from trans studies in the analysis. Trans studies scholars have pointed out that people with trans experiences have not been treated as legitimate knowers (experts) of their own lives in regard to trans-specific healthcare (Stryker, 2006). In line with Spade, we have "a desire for a deregulation of gender expressions and the promotion of selfdetermination of gender and sexual expression" (Spade, 2006, p. 319), and thus take an affirmative approach to individuals' autonomy, self-determination and access to gender-confirming medical procedures.

Feminist research has demonstrated the importance of gender for the organization of society, in terms of labour, violence, care and health to name but a few aspects. To a great extent, gender also organizes our identities, relations and desires (Connell, 2012). While some argue for a binary understanding of gender, as an inherent biological essence, post-structural feminists and trans studies scholars have argued for an understanding of the gendered subject as constructed within the surrounding context (Butler, 1990; Elliot, 2016; Stryker, 2006). Our understanding of gendered bodies is contextual and cannot be reduced to our knowledge of sex differences. The differentiation of bodies into normal or deviant is hence produced within a specific social context and the position of "the normal" is constructed through repeated constructions of the Other (Butler, 2009; Spade, 2006).

\section{Material-SKS}

The Swedish Knowledge Support (SKS), "Good healthcare for adults with gender dysphoria", is a 117page document published in 2015 by the National Board of Health and Welfare (The National Board of Health and Welfare, 2015), a government agency working to ensure good and equal health, social welfare and healthcare for the Swedish population. The SKS contains 37 recommendations for trans-specific healthcare. The National Board of Health and Welfare led the work on the guidelines, with one expert group responsible for the research and another for prioritizing the recommendations. Most of these experts work clinically within trans-specific healthcare as psychiatrists, endocrinologists, surgeons, voice therapists, social workers, psychologists etc. The aims of the guidelines are stated as developing healthcare and treatment for adults with gender dysphoria and providing equal care for care-seekers. The targeted groups for SKS are healthcare providers within the field of transspecific care and decision-makers.

\section{Analytical Method}

Bacchi's WPR approach suggests seven questions for analysing policy documents (Bacchi, 2009), of which we have used the first six (see Table 1). ${ }^{1}$ In the first analytical step, IL read and reread the guidelines with the questions in mind and made notes in the margin. In the second step, recommendations (understood as suggestions or solutions to the problem) that dealt with evaluation, diagnosis and criteria for access were chosen and thoroughly analysed in relation to questions 1-3 (see Table 1). When relevant, parts of the description and explanation for the recommendations were also included in the analysis. This analysis (of questions 1-3) resulted in the identification of three principal problem representations, which were discussed in detail and revised with the other coauthors. In the next step, questions 4-5 were used to analyse the three problem representations we identified in the previous step. This analysis was grouped into two themes, one dealing with care-providers and another with care-seekers. The sixth question is used and addressed in the concluding discussion.

\section{Results and Discussion}

By analysing the recommendations within the guidelines, we identified three principal problem representations: (a) the problem of (non)linear gender, (b) the mental health paradox and (c) gender dysphoria as a psychiatric, psychological and psychosocial problem. After describing these three problem representations, we will discuss the silences and effects produced by them (questions 4-5).

\section{The Problems, their Assumptions and Genealogy}

\section{The Problem of (Non)Linear Gender}

In the recommendation for the length of the evaluation, it is stated:

The length of the evaluation should be individualized according to the person's social and medical situation. You [the evaluator] should be especially careful before initiating treatment that includes physical change if the

\footnotetext{
${ }^{1}$ The seventh question is "Apply this list of questions to your own problem representations" (Bacchi, 2009, p. 2). This question is a suggestion to turn a critical gaze on your own analysis and conclusions. Although relevant, we find this aspect to be beyond the scope of this particular paper.
} 
Table 1 Analytical questions and how they are used in the analysis (Bacchi, 2009, p. 2)

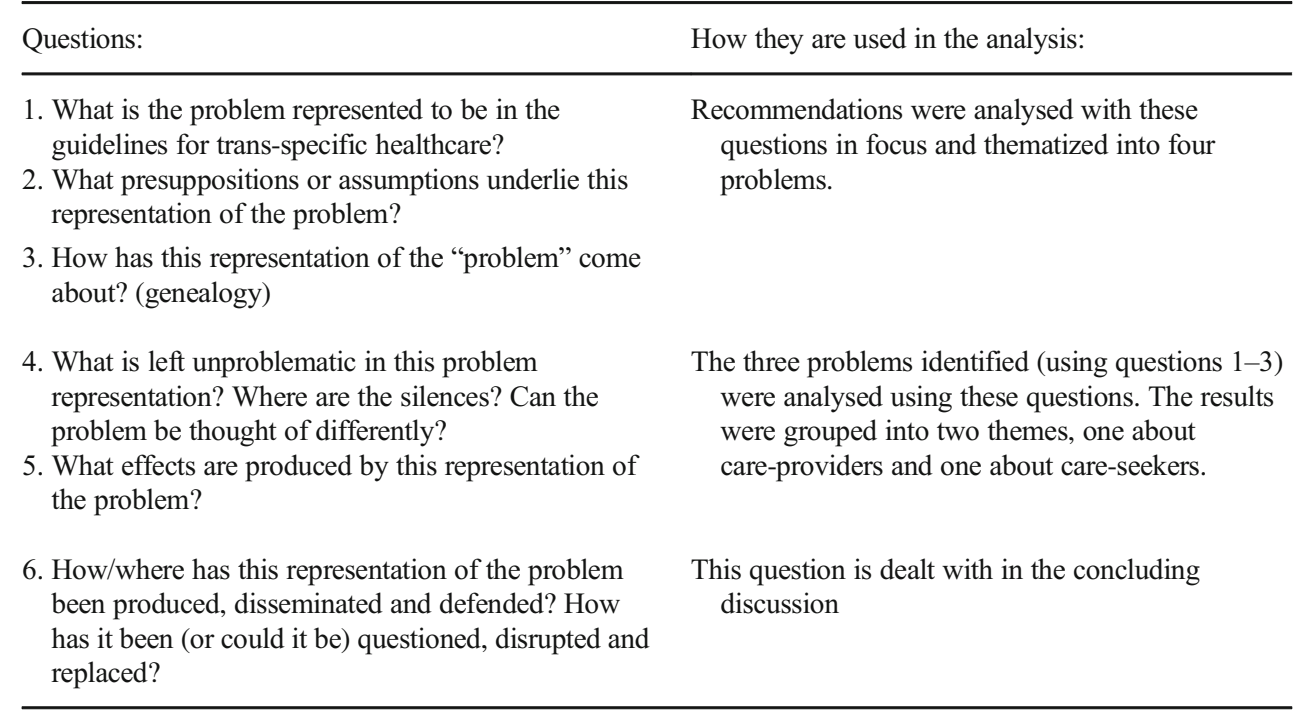

patient has just recently begun to explore their identity or alternative gender expression. It is not necessary for the person to have lifelong knowledge about their gender dysphoria, but caution is needed if the gender dysphoria is episodic or recently discovered. (p. 35)

Suggesting caution when dealing with care-seekers who lack a long-term and stable knowledge of their gender dysphoria and using the concept of "discovery" assumes that gender dysphoria is an inherent condition that is always already there to be discovered $(\mathrm{Q} 1, \mathrm{Q} 2)$. The same representation can apply to the term "episodic", since such an experience undermines a stable gender identity and ultimately makes a diagnosis of gender dysphoria impossible. Hence, gender dysphoria, and consequently also gender identity, is discursively constructed as a stable condition that does not change over time. A similar representation can be seen in the recommendation for access to surgery, which demands that gender-identity problems are "persistent" and "well-documented" (p. 52). In addition to the idea of a persistent gender stability, this recommendation also suggests that lack of documentation makes the diagnosis less substantiated. This implies that care-seekers' experiences and oral accounts are less trustworthy than care-providers' accounts, such as medical records. This type of representation of a stable gender has a long history in medical research and practice (Q3) and can be found in the 1968 governmental preparatory report for the current law, in which it is stated that the typical transsexual has experienced belonging to the other sex since before school age (SOU, 1968:28, p. 26).

This temporal aspect of gender identity, gender dysphoria and the evaluation process is also present in the recommendations for real-life experiences (RLEs), a phase of the evaluation in which the care-seeker is expected to live according to their identified gender:
Healthcare should offer persons who are evaluated for gender dysphoria help to plan and adjust a period of time when they live in the social role that matches the gender identity in which they want to be confirmed. (p. 36, recommendation for "living in accordance with one's gender identity"')

The formal motivation for retaining RLE as a part of the evaluation is that it makes it easier for the care-seeker to know whether living in their desired gender meets their expectations and that this reduces the risk of regret after irreversible treatment (p. 36). Regret is here represented as the problem to be solved (Q1). It alludes to the idea that care-seekers want to achieve a stable gender identity but that regret and a desire to "return" to the gender assigned at birth may be a problem (Q2) (see also Shuster, 2016). However, the prevalence of postsurgical regret is extremely low and, in addition, the guidelines state that there is no evidence in research that RLE reduces the risk of regret. Instead, the recommendation is based on clinical experience and international guidelines (p. 36). A historical representation (Q3) of the problem of unrealistic expectations among care-seekers can be found in Benjamin's warning to his patients: "the operation, even if successful, does not change you into a woman. Your inborn sex will remain male. You must be aware of this fact" (Benjamin, 1963, p. 293).

According to the guidelines, healthcare providers can have an advisory function in the decision about legal gender confirmation, and the guidelines state that the evaluator can, and often does, provide a certificate for the RLE period to the Legal Advisory Board. The requirement that a medical authority must provide a certificate implies that there is a problem with the trustworthiness of the applicant (Q2). According to Swedish law, an applicant for legal gender confirmation must "for a period of time [have] appeared in accordance with that gender identity" (SFS, 1972:119). However, the guidelines do 
not use the legislation to justify the RLE. "A period of time" in the legal paragraph is interpreted in the guidelines as: "one year is common in this context. In individual cases a longer or a shorter time period may be justified" (p. 13). Historically (Q3), it has been similarly argued that care-seekers should "for at least some years /.../ demonstrate their abilities to master a life in the opposite sex role" (SOU, 1968:28, p. 31).

In the recommendation for RLE, the social gender role is discursively connected to gender identity. While the guidelines do allow for non-stereotypical gender performances in relation to the RLE, the discursive connection between gender role and gender identity still assumes that there is only a single social gender role possible for each gender identity (Q2). A similar formulation can be found in the recommendation for the provision of appliances (in the evaluation chapter):

The healthcare provider should offer appliances such as wigs, breast prostheses, penile prostheses and binders (breast bandage) in order to facilitate patients to live in the social role that matches the gender identity in which they want to be confirmed. (p. 37)

This suggests that care-seekers have a problem in matching their gender identity with their social role (Q1) and need assistance to do so. Together with the recommendation for RLE and the Swedish legislation on legal and genital gender reassignment, which requires that an applicant has "consistently appeared in accordance with that gender identity, for example in the family, in school, at the workplace and in other public contexts" (p. 13), this indicates a problem of mismatching or inconsistent appearance among care-seekers. This assumption can be interpreted to mean that, when the social gender role does not match the self-proclaimed gender identity, authenticity can be questioned (Q2). Following this logic, the social gender role becomes the visible and measurable dimension of gender identity. That the social gender role is an extension of gender identity in dominant medical discourses is something feminist researchers have highlighted (Alm, 2006; Butler, 1990). However, while some feminist and trans scholars have identified a biologically deterministic understanding of gender and trans experiences within psychomedical discourse (Elliot, 2016; Sanger, 2008), gender identity is not visibly constructed as a biological essence in the SKS guidelines. However, it is still naturalized as a fixed essence that is stable over time.

In contrast to the problem of non-linear gender, the guidelines state that care-seekers do not have to want to undergo all the available medical procedures in order to be eligible for access to care and that "two individuals who have the same diagnosis will not necessarily receive the same care interventions" (p. 22). Hence, the guidelines seem to be intended to solve a problem of a rigidly standardized care approach and a problem of care-seekers having received inappropriate care ( $p$.
22). An "all or nothing" approach is visible in the governmental report of 1968, which states that a "strong demand for all interventions" is an important diagnostic sign (SOU, 1968:28, p. 29, our emphasis). Similarly, critical scholars have shown that a demand for surgery is implicitly constructed as a required symptom of transsexualism (Alm, 2006, 2018; Kroon, 2008). This has been argued as being a way of ensuring that the trans embodiment becomes as linear as possible (Alm, 2018). It thus seems as though the current guidelines deviate from these previous assumptions and demands, opening up the possibility for care-seekers to undergo only some of the available medical procedures if they do not want or need them all, or are unable to proceed with some. Hence, the problem representation of (non) linear gender is double-edged. On the one hand, there is a problem of non-linearity in the relationship between a person's social gender role and their gender identity and in relation to the stability of gender identity. Such non-linearity is a problem that can supposedly be solved by an individualized real-life experience (RLE) of suitable length, and appliances that can facilitate the matching between social gender role and gender identity. On the other hand, there is a problem with a care model that is too standardized. This is resolved by recommending flexibility with regard to which medical procedures care-seekers wish to undergo.

\section{The Mental Health Paradox}

For all surgical interventions mentioned in the knowledge support's text and recommendations, the following general criteria apply:

/... If pronounced medical or mental issues exist, they must be evaluated and treated as far as possible. (p. 52)

The recommendation above suggests that it is problematic to grant access to surgical interventions for a care-seeker with untreated medical or mental issues (Q1). Hence, it suggests that care-seekers are more appropriate candidates for genderconfirming surgical procedures if they are mentally healthy. The guidelines also state that untreated mental illness can make the evaluation and treatment more difficult (p. 32), but it is not explained why. At the same time, it is stated that "the diagnostic evaluation should not be unnecessarily delayed by psychiatric comorbidity" (p. 32, our emphasis).

In the guidelines, gender dysphoria is defined as "psychological suffering and/or impaired functioning in everyday life that is caused by the gender identity not matching the registered sex" (p. 113). Hence, the diagnosis requires the presence of psychological suffering/impaired functioning, and a diagnosis is necessary for access to care, but paradoxically, the guidelines state that access to medical procedures should be postponed until after treatment of any mental ill health. 
Adding to this paradox, research shows that care-seekers' mental health improves after access to medical procedures (Dhejne, Van Vlerken, Heylens, \& Arcelus, 2016). Studies have also shown that the evaluation process and waiting for medical procedures themselves contribute to mental ill health (Bremer, 2011; Linander, Alm, Hammarström, \& Harryson, 2017). Previous research confirms that mental stability has been privileged in the evaluation and has facilitated access to care (Bremer, 2011; Dewey \& Gesbeck, 2017).

In addition to this, the guidelines highlight that mental illness among people with trans experiences can stem from marginalization, discrimination, cisnormativity and heteronormativity. Even back in 1968, the government report (Q3) pointed out that it is difficult to appear in the opposite gender role in society and that psychological issues are an "adequate reaction to the basic problem" (SOU, 1968:28, p. 27). However, the "basic problem" - transsexualism - is represented as an individual pathology in the 1968 governmental report (SOU, 1968:28) and the focus on mental health and mental healthcare providers in the SKS guidelines seems to build upon and reproduce this notion. In the next section, we will look more closely at this construction of the problem.

\section{Gender Dysphoria as a Psychiatric, Psychological and Psychosocial Problem}

Diagnosing gender dysphoria should be undertaken by care professionals who have competence to use the DSM and ICD [diagnostic tools] systems, and who have documented capacity to recognize and diagnose coexistent psychiatric problems and differential diagnoses. In addition, those diagnosing should have good knowledge and experience of gender dysphoria, or alternatively be supervised by someone who has. (p. 32)

The focus on mental health professionals presupposes that care-seekers have a problem of a psychiatric or psychological character $(\mathrm{Q} 1)$. These recommendations, together with the diagnostic criteria for gender dysphoria in DSM-5 (American Psychiatric Association, 2013), also builds on the premise that it is possible for an external evaluator to diagnose gender dysphoria $(\mathrm{Q} 2)$. This evaluator has to possess a certain kind of knowledge - psychiatric knowledge. The concept of "suspected gender dysphoria" appears several times in the guidelines (pp. 40, 41, 42). When gender dysphoria is conceptualized as something that can be suspected, it is assumed (Q2) that it can be decided upon or diagnosed by healthcare providers but is not something that care-seekers themselves can know and decide upon.

Since 1980, trans experiences have been formally categorized as a psychiatric illness, but also before this trans experiences were medicalized and associated with mental illness
(Dewey \& Gesbeck, 2017) (Q3). Endocrinologist Benjamin stated as early as 1966 that psychiatric evaluation should precede access to surgery (Benjamin, 1966). Similarly, the guidelines' recommendation about diagnosing gender dysphoria frames care-providers as competent to identify "coexisting psychiatric problems" (Q1). The use of the concepts "coexisting" and "comorbidity" (p. 32) suggests that the primary problem (gender dysphoria) is psychiatric and that it constitutes a mental health problem. This representation of the problem might be connected to an understanding of trans experiences as an individual psychopathology, or as a mental illness in itself (Q2).

Psychosocial dimensions that are relevant to the evaluation of gender dysphoria include the person's access to support from those close to them. (p. 34, recommendation for psychosocial evaluation)

According to the guidelines, it is important to evaluate the care-seeker's psychosocial resources (e.g. "finances, accommodation, employment, relationships, children and plans for the future") (p. 34) and to examine their non-medical needs, in order for the "treatment" to be successful (Q1). This implies that care-seekers may have psychosocial problems that require evaluation (Q2). While the guidelines do not state how the results of this part of the evaluation should affect the possibilities of accessing care, the government report of 1968 states (Q3): "before medical and legal interventions, the social circumstances should be under control and a beneficial environment should be created", adding that "sometimes the social position or other circumstances suggest a restrained approach to profound medical or legal interventions" (p. 31). A previous study showed that social factors such as occupational choice and marital status have been reasons for the denial of access to gender-confirming medical procedures in a range of contexts (Denny, 1992).

Several additional recommendations concern psychosocial problems:

Healthcare should offer persons with gender dysphoria or suspected gender dysphoria therapy and counselling in order to explore their gender identity and limit mental ill health. (p. 41, recommendation for therapy and counselling)

Healthcare should offer psychosocial support to people with gender dysphoria or suspected gender dysphoria. This kind of support can be relevant during the evaluation and treatment period and after sex-correcting treatment. (p. 42, recommendation for psychosocial support) 
According to these suggestions, care-seekers are expected to have psychosocial problems that can be resolved through support, therapy and counselling (Q1). The recommendation for therapy and counselling assumes that care-seekers need to explore their gender identity, that they are able to do so in therapy and that therapy limits mental ill health (Q2). The guidelines mention a wide range of aims for psychotherapy and psychosocial interventions: opportunities to explore one's gender identity, deal with internalized transphobia, get support from social networks, improve body image, be able to deal with psychological challenges and contribute to better social adaptation (p. 22, p. 40). While some of these factors are obviously connected to social conditions for people with trans experiences, the recommendations in the guidelines target the individual care-seeker. At the same time, the guidelines also state that mental health issues among people with trans experiences can be due to vulnerability and discrimination connected to cisnormativity and heteronormativity (p. 32).

According to the guidelines, the psychosocial evaluation should also preferably include meetings with close family and friends. This assumes that relatives have information that evaluators need, information that the care-seekers themselves cannot provide (Q2). It can also be interpreted as an opportunity to corroborate care-seekers' accounts, and if so, it delegitimizes the care-seeker's role as an expert on their own experiences and feelings.

Another aim of the recommendation for therapy and counselling is to "create realistic strategies to achieve success in one's relationships, education and working life" (p. 40). "Improved functioning and assimilation into working life" (pp. 90, 92) is also used to justify the economic costs of all the recommendations in the guidelines. This assumes that access to gender-confirming medical procedures may create success in working life (Q2) (see also Alm, 2006; SOU, 1968:28).

Psychosocial support is also said to potentially reduce the risk of regret through better support from relatives; hence, psychosocial support contributes to resolving the supposed problem of regret $(\mathrm{Q} 1)$. The function of therapy and psychosocial support is not only to benefit the care-seeker but is also said to be essential in order for the evaluating team to feel confident about the evaluation result and for them to make well-informed decisions with regard to "treatment" (p. 8). The emphasis on psychosocial interventions and the fact that they are not only for the sake of the care-seekers might imply that these interventions are a part of the evaluation process (but categorized as an intervention) and a way of retaining the gatekeeping function among the mental health professionals within trans-specific healthcare $(\mathrm{Q} 2)$.

For migrants not holding a residence permit, the guidelines suggest that the treating medical doctor should decide on what is "healthcare that cannot wait" (p. 23), which is the key phrase in the law on access to healthcare for undocumented migrants and asylum seekers. This assumes that gender- confirming medical procedures are not, in and of themselves, healthcare that cannot wait, at least for some people (Q2). An exception in the guidelines is made for people who have already started on hormones in their home country, who should be referred to trans-specific healthcare for continued treatment; hence, this constitutes healthcare that cannot wait.

\section{Silences and Effects}

The problems represented in the guidelines that we have identified through analysing the recommendations are: "the problem of (non)linear gender", "the mental health paradox" and "gender dysphoria as a psychiatric, psychological and psychosocial problem". These problem representations enable some kinds of action and intervention, while others are silenced or suppressed. By allocating the decision-making power to healthcare professionals with psychiatric knowledge, these representations of the problem silence the autonomy and self-determination of care-seekers and construct an unknowledgeable care-seeking subject. The evaluator's function as the person who diagnoses, provides a certificate to the Legal Advisory Board and referral for medical procedures and offers psychosocial support and therapy also silences the relationship of dependency between the care-seeker and the careprovider and conceals the effects of such dependency on the therapeutic relationship and quality of care (Hale, 2007; Linander et al., 2017; Shuster, 2016; SOU, 2017:92). These problem representations also block alternative models of decision-making in trans-specific healthcare, such as an informed consent model.

We also argue that these problem representations silence a critical analysis of cisnormativity, although it is mentioned in the guidelines, along with heteronormativity, as a cause of vulnerability and mental ill health. For example, the fact that the guidelines are reconstructing the same normality that they describe as problematic is silenced. A concrete example is how the emphasis on matching a person's social role with their gender identity silences the fact that only certain social gender roles are intelligible in society (Butler, 2009). The insistence on "consistent gender appearance" furthermore precludes the possibility that gender appearances do not have to be either stable over time or consistent in terms of the use and mixing of different clothes and attributes in a given moment, because gender performance, from our perspective, is dependent on both a temporal and spatial context. When mentioned in the guidelines, cisnormativity is also reshaped within a medicalization discourse; it is still the people with trans experiences who are constructed as vulnerable; it is not society that is creating situations of vulnerability. Additionally, the extensive focus on psychiatric/psychological evaluation and knowledge silences the possibility that it could be physical features or the social context that is problematic. This construction 
might contribute to paternalistic approaches and further pathologize and medicalize trans experiences.

The problem representations also silence the possibility of a gender-euphoric subject, an individual who does not suffer psychologically from their gender identity but enjoys altering gender expressions and using gender-transforming technologies (see Preciado, 2013). Gender euphoria can be seen as the positive homologue of gender dysphoria and, if silenced, might conceal important reasons for gendered bodily alterations (Ashley, 2019). A gender-euphoric subject might not be eligible for state-funded gender-confirming medical procedures but, regardless of that, they are silenced in the guidelines and, hence, have no space either inside or outside state-funded trans-specific healthcare.

The problem representations described above have two overarching subjectification effects, one for care-seekers and one for healthcare providers. In relation to these two different subjectification effects, we will now also discuss the discursive and lived effects and the silencing of different understandings of the problem. We begin with a discussion on healthcare providers because the effects of these constructions ultimately have discursive, subjectification and lived effects for care-seekers.

\section{Psychiatric or Psychological Healthcare Providers Deciding on Access to Care}

The recommendations in the SKS construct the whole of trans-specific healthcare as a specialized type of care. The healthcare-providing subject who is competent to decide upon access to care is someone who works in a multidisciplinary team and has psychiatric/psychological knowledge. This representation can be traced in references to the "suspicion" and "detection" of gender dysphoria, which alludes to the idea that care-providers are the principal knowledgeable subjects.

The problem representations reconstruct and preserve the gatekeeping function within certain specialized teams. This specialization might become a hindrance if care-seekers are dissatisfied with the care they receive from one team and seek alternatives. It also constructs formal trans-specific healthcare as having a monopoly. Even though state-funded healthcare may not provide care for everyone, and may exclude, for example, a gender-euphoric individual, the recommendation in the guidelines provides no room outside trans-specific healthcare for providing gender-confirming medical procedures.

Hence, care-providers outside of formal trans-specific healthcare are positioned as unknowledgeable and are not trusted to make the right decisions about access to genderconfirming medical procedures. This might have lived effects in terms of improving the opportunities for care-seekers to meet knowledgeable care-providers and not get "stuck" in other parts of healthcare (see also Linander et al., 2017). The problem representations can also contribute to more geographically equal care if these teams adhere to the guidelines (which has, however, been questioned (SOU, 2017:92) and problematised (Shuster, 2016)) because the guidelines provide detailed descriptions of different medical procedures and which medical procedures should be offered and subsidized. However, the specialized approach can also create geographical inequalities due to some people living far away from the centralized team and having to travel long distances to access care.

\section{The Care-Seeker (Un)Deserving of Access to Care}

The subjects who are constructed as deserving access to care are suffering but mentally healthy, hold a residence permit (if not yet citizens) and are people who have a consistent gender identity and appearance over time. By providing recommendations intended to resolve the "all or nothing approach", the guidelines also enable a subject who has, or wants to have, a non-linear embodiment as being eligible for care. This might have lived effects; for example, in terms of increased access to care for non-binary people (Linander et al., 2019). However, the guidelines still have subjectification effects relating to linear gender. Since gender identity and social gender roles are socially constructed as binary, either male or female, nonbinary care-seekers might have difficulty in becoming intelligible as deserving care. Similarly, binary-identified careseekers who do not perform gender in stereotypical ways might have difficulties in meeting the criteria for consistency in gender expression. One lived effect that these constructions of gender identity and social gender roles can have in care practices is that, in order to pass the evaluation, the careseeker has to perform gender in particular and stereotypical ways that match the normative ideals of how gender identity is connected to a certain social gender role.

In the guidelines, it is supposed that the problem of regret will be resolved through RLE and psychosocial support. The problem of regret and how it is represented discursively constructs gender as stable, and a change in gender identity after receiving gender-confirming medical procedures is perceived as a failure. The guidelines do point out that, among those few who do regret undergoing gender-confirming medical procedures, this regret is associated with poor surgical results and lack of support from their social network. Still, the conceptualization of regret silences a more fluid understanding of gender identity. Hence, the subject who is eligible for access to care must have had a consistent gender identity over time and is expected to continue with this in the future. This discursive construction of gender as stable can have the effect that the evaluation continues to focus on and privilege childhood behaviour and a consistent social gender role and performance over time (Linander et al., 2019). 
Adapting the length of the evaluation to individual needs might limit unnecessary waiting time, but it might also increase the waiting time for someone who has mental or medical issues or has episodically or recently "discovered" gender dysphoria. The subject who can be diagnosed with gender dysphoria is expected to be suffering. Hence, in order to gain access, the care-seeker has to suffer precisely the "right" amount: enough to be distressing, but not so much that it can be classified as a mental illness. Apart from the fact that such an understanding is a paradox, the risk of arbitrary assessment cannot be ignored.

The emphasis on psychiatric knowledge, evaluation and psychosocial therapy and support reinforces gender dysphoria as a psychopathology. However, the focus on psychosocial support might also have effects in terms of improved access to follow-up and continued support, which previous studies have shown to be lacking (Linander et al., 2017). The guidelines do not completely silence the relationship of dependency between care-seeker and care-provider, because they do discuss the dual roles of evaluators: both evaluating the need for care and providing support. However, this does not seem to prevent a reproduction of the gatekeeping function allocated to mental health care providers.

Discursively, the guidelines construct gender-confirming medical procedures as a way to create respectable and productive working citizens who can contribute to society (Denny, 2004; Foucault, 1990). Thus, a subject who is constructed as eligible for gender-confirming medical procedures could be interpreted as someone with the potential to become such a citizen. In addition, according to the guidelines, the careseeking subject's social life should also be thoroughly evaluated before they are granted access. There might be a socioeconomic lived effect of these constructions, as care-seekers may have different levels of opportunity to present a well-ordered social life, in terms of socioeconomic situation and symbolic resources related to class (Bremer, 2011; SOU, 1968:28).

The recommendations relating to care provision for people without a residence permit, together with the answers from different teams in a survey (SOU, 2017:92), indicate that asylum seekers who have not started taking hormones prior to entering Sweden will not be granted access to the evaluation or to medical procedures. This suggests that trans-specific healthcare is constructed as healthcare that can wait, and asylum seekers and undocumented migrants are constructed as not deserving of care. For other groups who are constructed as vulnerable in the guidelines, trans-specific healthcare should make an effort to provide care. This can have lived effects in terms of more equal access to care, although the idea that careseekers will become productive citizens after access contradicts such ambitions. The exception is thus asylum seekers and undocumented migrants, who are not constructed as deserving of the same kind of efforts to enable their access to care.

\section{Concluding Discussion}

Denny (2004) argues that trans-specific healthcare providers have been affected, and partially changed, through practice due to an overall change in the understanding of trans experiences. The guidelines analysed in this paper seem to have been influenced by a less linear and more non-binary conceptualization of gender than previous versions, which may create opportunities for gender-non-conforming people to become eligible for access to gender-confirming medical procedures. These guidelines, like the diagnostic criteria in the latest version of DSM (American Psychiatric Association, 2013), attempt to decouple gender incongruence from the distress caused by gender variation and hence represent steps towards depathologization. The guidelines also acknowledge cisnormativity as a cause of mental ill health and vulnerability. At the same time, two of the three problem representations that we have identified tie into psychiatric/psychological or mental issues, and through these representations, the guidelines reinforce the belief that trans experiences are an individual psychopathology.

Gender dysphoria, as a phenomenon, is still constructed in a similar way to older models, such as the transsexual model (Denny, 2004). This is also apparent in the representation of gender identity as an essence, which is stable over time. This (bio)medicalized understanding of trans experiences is not able to see the connections between the distress of gender dysphoria and the distress caused by societal prejudice or violence. The individualized construction of gender-identity problems silences the societal discourses that construct non-normative gender identity as in need of correction (Burke, 2011; Winters, 2006). Hence, in order to provide alternative problem representations and enable other kinds of action, this understanding of trans experiences and gender needs to be discussed and challenged. Such alternatives should not, however, fall into the trap of jeopardizing access to care by constructing genderconfirming medical procedures as cosmetic (Denny, 2004).

From a post-structural perspective, gender dysphoria can be understood as constructed in time and space, since the specific meaning of the phenomenon is contested and dependent upon (psycho)medical knowledge production and social norms of gender. This is not to suggest that the sense of gendered self of people with trans experiences is not "real" (Butler, 2014), but it locates the "problematic" nature of this gender identity and the related psychosocial problems within a social context that often renders trans embodiment unintelligible and positions people with trans experiences at risk of different forms of violence (Butler, 2009; Kennedy, 2013). A post-structural lens can also facilitate an understanding of the diagnostic practice as a negotiation of power, meaning and space for action, which is influenced by history, social norms and politics (McGann, 2011). Such an understanding enables critical examinations of how different norms shape clinical 
practice and how people with specific positions and knowledge, in this case psychiatric care-providers, gain greater space for action.

During the last two decades, decision-making models within trans-specific healthcare have increasingly been discussed (Denny, 2004; Deutsch, 2012; Dewey \& Gesbeck, 2017; Pimenoff \& Pfäfflin, 2011). A central issue within this discussion has concerned access to gender-confirming medical procedures: who should decide on care-seekers' access to care, how should this be done and what role should mental healthcare professionals take? An informed consent approach to hormonal treatment has been used in several US contexts, and this has been accompanied by an affirming and nonpathologizing approach to trans experiences. In a US context, the informed consent model typically means that you do not need approval or a letter from a mental health professional (or two) to start on hormones (Davidson et al., 2013; Deutsch, 2012; Winters, 2006). However, in many cases, these socalled informed consent models have involved some kind of gatekeeping or assessment, for example by a general practitioner or endocrinologist assessing the psychosocial situation, "readiness" and possible need for mental health assessment (Coleman et al., 2011; Davidson et al., 2013; Deutsch, 2012). The discussion around informed consent models needs to be positioned in relation to differences in healthcare systems. For example, the issues with different decision-making models are probably different in contexts where care-users are dependent on healthcare insurance or pay for medical procedures themselves compared to welfare states such as Sweden, where tax revenue pays for gender-confirming medical procedures. In Sweden, informed-consent models have not yet been widely discussed, and this study might serve as a contribution to such a discussion, in which not only different decisionmaking models have to be considered, but also what factors the decisions on access to care should be based upon.

\section{Implications}

The SKS will probably be revised in the next couple of years (SOU, 2017:92), and we believe that the issues addressed in this paper can be useful in such a revision. We also see a need for deeper involvement in the revision process by care-seekers with a broad range of experiences in order to address some of the issues raised in this study (T'Sjoen, Motmans, Arcelus, \& Bouman, 2017). In addition to this, we argue that it is important for the guidelines to be implemented by all of the involved teams in Sweden. We believe that this is important despite the critique brought forward in our analysis because, in these guidelines, some important steps have been taken in the right direction based on ideals of self-determination and transaffirmative healthcare.

Our analysis also has implications for a broader context because the Swedish guidelines have been strongly influenced by the international guidelines issued by the World Professional Association for Transgender Health (Coleman et al., 2011). The discourses and issues described and discussed in this study are thus not unique to Sweden and are connected to more general psychomedical discourses about trans experience and gender dysphoria. Thus, the critique presented here can also be useful when constructing, revising or analysing guidelines for trans-specific healthcare in other contexts.

Authors' Contributions IL analysed and interpreted the guidelines while continuously discussing preliminary findings and interpretations with all authors. A first draft of the manuscript was prepared by IL which all other authors then contributed significantly to.

Funding Information Open access funding provided by Umea University. This study was financed by the Swedish Research Council (grant no. 344-2011-5478).

Data Availability The datasets analysed during the current study are available in the National Board of Health and Welfare repository, the guidelines (in Swedish) can be found on their homepage: https://www. socialstyrelsen.se/globalassets/sharepoint-dokument/artikelkatalog/ kunskapsstod/2015-4-7.pdf

\section{Compliance with Ethical Standards}

Conflict of Interest The authors declare that they have no competing interests.

\section{Ethics Approval and Consent to Participate Not applicable.}

\section{Consent for Publication Not applicable.}

Open Access This article is licensed under a Creative Commons Attribution 4.0 International License, which permits use, sharing, adaptation, distribution and reproduction in any medium or format, as long as you give appropriate credit to the original author(s) and the source, provide a link to the Creative Commons licence, and indicate if changes were made. The images or other third party material in this article are included in the article's Creative Commons licence, unless indicated otherwise in a credit line to the material. If material is not included in the article's Creative Commons licence and your intended use is not permitted by statutory regulation or exceeds the permitted use, you will need to obtain permission directly from the copyright holder. To view a copy of this licence, visit http://creativecommons.org/licenses/by/4.0/.

\section{References}

Alm, E. (2006). "Ett emballage för inälvor och emotioner": Föreställningar om kroppen i statliga utredningar från 1960- \& 1970-talen. ["A container of intestines and emotions": Conceptions of the body in Swedish Governmental official reports from the 1960s and 1970s.] Gothenburg: Gothenburg University Press.

Alm, E. (2018). What constitutes an in/significant organ? The vicissitudes of juridical and medical decision-making regarding genderaffirming surgery for intersex and trans people in Sweden. In G. 
Griffin \& M. Jordal (Eds.), Body, migration, re/constructive surgeries: Making the gendered body in a globalized world (pp. 225-240). New York: Routledge.

American Psychiatric Association. (2013). Diagnostic and statistical manual of mental disorders (5th ed.). Washington DC: American Psychiatric Association.

Ashley, F. (2019). Gatekeeping hormone replacement therapy for transgender patients is dehumanising. Journal of Medical Ethics, 45(7), 480-482.

Bacchi, C. (1999). Women, policy and politics: The construction of policy problems. London: Sage.

Bacchi, C. (2009). Analysing policy: What's the problem represented to $b e$ ? Frenchs Forest, NSW: Pearson.

Benjamin, H. (1963). "I want to change my sex!” Dr. Benjamin's reply. Sexology, 30(5), 292-295.

Benjamin, H. (1966). The transsexual phenomenon. New York: Julian Press.

Bremer, S. (2011). Kroppslinjer: kön, transsexualism och kropp $i$ berättelser om könskorrigering [Bodylines: Gender, transsexualism and embodiment in narratives of gender correction.]. Gothenburg University, Göteborg: Makadam. Retrieved from http://hdl.handle. net $/ 2077 / 26653$

Burke, M. C. (2011). Resisting pathology: GID and the contested terrain of diagnosis in the transgender rights movement. Advances in Medical Sociology, 12, 183-201.

Butler, J. (1990). Gender trouble: Feminism and the subversion of identity. London/New York: Routledge.

Butler, J. (2009). "Performativity, precarity and sexual politics." Talk given at Universidad Complutense de Madrid. June 8, 2009. Retrieved from http://www.aibr.org/antropologia/04v03/criticos/ 040301b.pdf

Butler, J. (2014). Gender performance: The TransAdvocate interviews Judith Butler. The TransAdvocate. Retrieved from https://www. transadvocate.com/gender-performance-the-transadvocateinterviews-judith-butler_n_13652.htm

Coleman, E., Bockting, W., Botzer, M., Cohen-Kettenis, P., DeCuypere, G., Feldman, J., Fraser, L., Green, J., Knudson, G., Meyer, W. J., Monstrey, S., Adler, R. K., Brown, G. R., Devor, A. H., Ehrbar, R., Ettner, R., Eyler, E., Garofalo, R., Karasic, D. H., Lev, A. I., Mayer, G., Meyer-Bahlburg, H., Hall, B. P., Pfaefflin, F., Rachlin, K., Robinson, B., Schechter, L. S., Tangpricha, V., van Trotsenburg, M., Vitale, A., Winter, S., Whittle, S., Wylie, K. R., \& Zucker, K. (2011). Standards of care for the health of transsexual, transgender, and gender-nonconforming people, version 7. International Journal of Transgenderism, 13(4), 165-232. https://doi.org/10.1080/ 15532739.2011.700873.

Connell, R. (2012). Gender, health and theory: Conceptualizing the issue, in local and world perspective. Social Science \& Medicine, 74(11), 1675-1683. https://doi.org/10.1016/j.socscimed.2011.06.006.

Coveney, J. (2010). Analyzing public health policy: Three approaches. Health Promotion Practice, 11(4), 515-521.

Davidson, A., Franicevich, J., Freeman, M., Lin, R., Martinez, L., Monihan, M., . . . Zevin, B. (2013). Tom Waddell Health Center protocols for hormonal reassignment of gender. Retrieved from http://www.twtransgenderclinic.org/wp/wp-content/uploads/2012/ 06/TG-protocols-2011-revision.pdf

Denny, D. (1992). The politics of diagnosis and a diagnosis of politics: The university-affiliated gender clinics, and how they failed to meet the needs of transsexual people. Chrysalis Quarterly, 1(3), 9-20.

Denny, D. (2004). Changing models of transsexualism. Journal of Gay \& Lesbian Psychotherapy, 8(1-2), 25-40.

Deutsch, M. B. (2012). Use of the informed consent model in the provision of cross-sex hormone therapy: A survey of the practices of selected clinics. International Journal of Transgenderism, 13(3), 140-146.
Dewey, J. M., \& Gesbeck, M. M. (2017). (Dys)functional diagnosing mental health diagnosis, medicalization, and the making of transgender patients. Humanity and Society, 41(1), 37-72.

Dhejne, C., Öberg, K., Arver, S., \& Landen, M. (2014). An analysis of all applications for sex reassignment surgery in Sweden, 1960-2010: Prevalence, incidence, and regrets. Archives of Sexual Behavior, 43(8), 1535-1545. https://doi.org/10.1007/s10508-014-0300-8.

Dhejne, C., Van Vlerken, R., Heylens, G., \& Arcelus, J. (2016). Mental health and gender dysphoria: A review of the literature. International Review of Psychiatry, 28(1), 44-57. https://doi.org/ 10.3109/09540261.2015.1115753.

Elliot, P. (2016). Debates in transgender, queer, and feminist theory: Contested sites. London: Routledge.

Foucault, M. (1990). The history of sexuality. Vol. 1, The will to knowledge. Harmondsworth: Penguin.

Foucault, M. (1991). Questions of method. In G. Burchell, C. Gordon, \& P. Miller (Eds.), The Foucault effect: Studies in governmentality. Chicago, IL: University of Chicago Press.

Hale, C. J. (2007). Ethical problems with the mental health evaluation standards of care for adult gender variant prospective patients. Perspectives in Biology and Medicine, 50(4), 491-505.

Hirschfeld, M. (1910). Die Transvestiten: eine Untersuchung über den erotischen Verkleidungstrieb: mit umfangreichen casuistischen und historischen Material. Berlin: A. Pulvermacher.

Kennedy, N. (2013). Cultural cisgenderism: Consequences of the imperceptible. Psychology of Women Section Review, 15(2), 3-11.

Kroon, A. (2008). Transsexuella taxonomier: Asymmetriska konstruktioner av kön och sexualitet. [Transsexual taxonomies: Asymmetric constructions of gender and sexuality]. Tidsskrift for kjønnsforskning, 32(3), 60-78.

Lane, M., Ives, G. C., Sluiter, E. C., Waljee, J. F., Yao, T.-H., Hu, H. M., \& Kuzon, W. M. (2018). Trends in gender-affirming surgery in insured patients in the United States. Plastic and Reconstructive Surgery Global Open, 6, e1738. https://doi.org/10.1097/GOX. 0000000000001738

Linander, I., Alm, E., Hammarström, A., \& Harryson, L. (2017). Negotiating the (bio)medical gaze: Experiences of trans-specific healthcare in Sweden. Social Science and Medicine, 174, 9-16. https://doi.org/10.1016/j.socscimed.2016.11.030.

Linander, I., Alm, E., Goicolea, I., \& Harryson, L. (2019). "It was like I had to fit into a category": Care-seekers' experiences of gender regulation in the Swedish trans-specific healthcare. Health, 23(1), 21-38. https://doi.org/10.1177/1363459317708824.

McGann, P. J. (2011). Troubling diagnoses. In P. J. McGann \& D. J. Hutson (Eds.), Sociology of diagnosis (Vol. 12, pp. 331-362). Bingley, UK: Emerald.

Pimenoff, V., \& Pfäfflin, F. (2011). Transsexualism: Treatment outcome of compliant and noncompliant patients. International Journal of Transgenderism, 13(1), 37-44.

Preciado, B. (2013). Testo junkie: Sex, drugs, and biopolitics in the pharmacopornographic era. New York: The Feminist Press.

Sanger, T. (2008). Trans governmentality: The production and regulation of gendered subjectivities. Journal of Gender Studies, 17(1), 41-53.

SFS. (1972:119). Lagen om fastställande av kön $i$ vissa fall [The law on determination of sex in some cases.]. Stockholm: Justitiedepartementet.

Shuster, S. M. (2016). Uncertain expertise and the limitations of clinical guidelines in transgender healthcare. Journal of Health and Social Behavior, 57(3), 319-332.

SOU. (1968:28). Intersexuellas könstillhörighet: förslag till lag om fastställande av könstillhörighet $i$ vissa fall [Sex of intersexuals: a proposal for a law on determination of sex in some cases]. Stockholm.

SOU. (2017:92). Transpersoner i Sverige: förslag för stärkt ställning och bättre levnadsvillkor [Trans persons in Sweden: suggestion for strengthened position and better life conditions]. (978-91-38- 
24711-2). Stockholm: Wolters Kluwer Retrieved from http://www. regeringen.se/rattsdokument/statens-offentliga-utredningar/2017/ 11/sou-201792

Spade, D. (2006). Mutilating gender. In S. Stryker \& S. Whittle (Eds.), The transgender studies reader (pp. 315-332). New York, NY: Taylor \& Francis.

Stryker, S. (2006). (De)subjugated knowledges: An introduction to transgender studies. In S. Stryker \& S. Whittle (Eds.), The transgender studies reader (pp. 1-17). New York, NY: Routledge.

The National Board of Health and Welfare. (2010). Transsexuella och övriga personer med könsidentitetsstörningar: rättsliga villkor för fastställelse av könstillhörighet samt vård och stöd [Transsexuals and other persons with gender identity disorder: Legal conditions for determination of gender identity, as well as healthcare and support] (978-91-86585-38-9). Retrieved from Stockholm: http:// www.socialstyrelsen.se/Lists/Artikelkatalog/Attachments/18087/ 2010-6-31.pdf

The National Board of Health and Welfare. (2015). God vård av vuxna med könsdysfori: nationellt kunskapsstöd [Good healthcare for adults with gender dysphoria: National knowledge support]. Stockholm: Socialstyrelsen.

T'Sjoen, G., Motmans, J., Arcelus, J., \& Bouman, W. (2017). The need of patient involvement in transgender health care research. The Journal of Sexual Medicine, 14(12), 1494-1495. https://doi.org/10.1016/j. jsxm.2017.09.019.

Walt, G., Shiffman, J., Schneider, H., Murray, S. F., Brugha, R., \& Gilson, L. (2008). "Doing" health policy analysis: Methodological and conceptual reflections and challenges. Health Policy and Planning, 23(5), 308-317.

Winters, K. (2006). Gender dissonance: Diagnostic reform of gender identity disorder for adults. Journal of Psychology \& Human Sexuality, 17(3-4), 71-89.

Publisher's Note Springer Nature remains neutral with regard to jurisdictional claims in published maps and institutional affiliations. 